\title{
Fostering citizenship in marginalised children through participation in Community of
}

\section{Philosophical Inquiry}

Claire Cassidy, Helen Marwick, Lynn Deeney, Gillian McLean and Kirsten Rogers

\begin{abstract}
Given the key drivers around citizenship education, children's rights, voice, and participation it is essential that all children are supported to engage in the society in which they live. This article explores how McCall's Community of Philosophical Inquiry (CoPI) (McCall 1991, 2009) might offer that support to children who are potentially marginalised due to their specific needs. The article presents three case studies of children at risk of being marginalised in school settings who participated in CoPI over a period of ten weeks. CoPI has features that may be conducive to the achievement of broad goals associated with children's voice and citizenship education. The article explores the ways in which these particular children engaged with CoPI and the impact of participation on their behaviour. The analysis of the accounts of their teachers supports the hypothesis that potentially marginalised children appear to benefit from the structure that is inherent in this form of practical philosophy.
\end{abstract}

\section{Keywords}

Philosophy with Children; marginalised children; citizenship; participation; children's voice

\section{Introduction}

What is entailed by citizenship education and its role within democratic societies has evolved to become increasingly broad and diverse. Formerly prevalent curricular components such as civics and civic education have been joined in educational discourse by broader conceptions, such as 'citizenship learning' (Biesta, Lawy and Kelly, 2015) and greater emphasis on critical thinking skills (Veuglers, 2007; Garratt and Piper, 2011) and democratic participation (Wall, 
2011; Bartels, et al., 2015). Curricular reform in Scotland in recent years reflects this trend, with the implementation of an inclusive curriculum for all children aged between three and eighteen, Curriculum for Excellence (CfE), within which the notion of the 'responsible citizen' features heavily (Scottish Executive, 2004). It should be noted that citizenship in Scottish schools is different from the rest of the UK. Rather than discrete classes for citizenship being taught, an embedded, integrated approach is advocated throughout the formal and informal curriculum. Further, in Scotland, what is done in schools is construed as Education for Citizenship rather than Citizenship Education. This indicates the general ethos and purpose of the topic in schools; that children are educated to participate in and engage with the world around them. Of course, this is not to deny that there are problems. Biesta (2008) criticises Scottish teachers for their tendency to avoid the political dimension of education for citizenship. There are also suggestions that if it is the responsibility of all, then no-one takes responsibility (Cassidy et al., 2014). CfE aims to promote four key features, namely, that children will become: Successful Learners; Confident Individuals; Effective Contributors and Responsible Citizens (Scottish Executive, 2004).

The aim of the present study is to explore the impact and potential benefit of participation in Community of Philosophical Inquiry (CoPI) on children who might be considered marginalised in their educational experiences. The article focuses on two of the four features: the Effective Contributor and the Responsible Citizen. The Responsible Citizen

'will have respect for others [and] a commitment to participate responsibly in political, economic, social and cultural life... develop knowledge and understanding of the world...; understand different beliefs and cultures; make informed choices and decisions; evaluate environmental, scientific and 
technological issues [and] develop informed ethical views of complex issues' (Scottish Executive 2004: 12).

The Effective Contributor will 'Communicate in different ways and in different settings, apply critical thinking in new contexts, [be able to] create and develop [and will] solve problems' (Scottish Executive, 2004: 12). It is suggested, here, that to do what is required of a responsible citizen, particularly in relation to participation, an individual must be able to do what is demanded of the effective contributor. Children are increasingly recognised as social actors in terms of their right to participate in policy formation and decision-making. This applies across the age range, with ample evidence emerging of the capability of young children, where appropriate conditions are established, to participate meaningfully in social and political processes (E.g. MacNaughton et al., 2007). However, for some children, this is more challenging, particularly for those who are marginalised or who experience barriers to inclusion for any reason, whether arising from social background, individual, behavioural characteristics, specific learning difficulties or a disability. Barriers may also be presented to the child by the curriculum and pedagogy employed by the teacher.

Following the Education (Additional Support for Learning) Act (Scotland) (2004), all children should able to access, attend and be included in mainstream schools. The consequence is therefore that teachers will very likely have in their classrooms a number of children deemed to have Additional Support Needs (ASN). ASN is a much broader term than Special Educational Needs (SEN) as frequently used elsewhere. The notion of SEN privileges a medical model, within which the child may be seen as being deficient in some way, whereas the notion of ASN is arguably more inclusive and accords much more significance to social factors and other contexts that influence the child's need for support (Moscardini, 2013). Children may be described as having ASN if, for example, they have been absent from 
school through ill health, if they have English as an Additional Language, if they are particularly able or struggle academically, or if they have a recognised diagnosis such as dyslexia or Autistic Spectrum Disorder (ASD). For many of the children described as having ASN, opportunities for full engagement with the curriculum and society more generally may be limited or constrained, and the likelihood of being socially marginalised is, therefore, higher. If it is the case that the Scottish curriculum is for all children equally and that each child is expected to be confident while being successful in their learning and that, at the same time, they are able to be responsible citizens who contribute effectively, it follows that mechanisms should be put in place that this might happen.

While the concept of 'inclusion' and the advocacy of an inclusive pedagogy are well established in educational contexts, marginalisation arguably remains a risk for many children, not least because of the complexity and contested nature of the concept of inclusion (Messiou, 2012), but also because of the attitudinal and practical challenges inherent in enacting inclusion. Inclusive pedagogy is defined by Florian and Spratt (2013: 119) as ' ... an approach $(\ldots)$ that supports teachers to respond to individual differences between learners, but avoids the marginalisation that can occur when some students are treated differently'. This definition, of course, raises further questions about precisely how conditions can be created for inclusive pedagogy to be enacted, questions that are explored in the context of teacher education by Florian and Spratt (2013). Conn (2014) also highlights specific issues around the peripheral social engagement afforded to children with specific needs such as autism. Increasingly, the discourse of rights has been associated with the concept of inclusion and in particular, the notion of children's participation rights and advocacy of pupil voice in educational settings (e.g. Lundy, 2007). Messiou (2012: 1313) brings these ideas 
together in her studies of pupil voice and marginalisation by putting learners' voices 'at the centre of the process of inclusion'.

\section{Community of Philosophical Inquiry}

In the present article we present individual case studies of children who may be at risk of marginalisation in the sense that they may be treated differently from their school peers for a range of reasons related to their ASN. It focuses on the use of a distinctive and arguably inclusive approach, McCall’s Community of Philosophical Inquiry (CoPI) (McCall 1991, 2009; Cassidy, 2007, 2012), which may enable these children to exercise 'voice'. There is a growing volume of international evidence of the educational value of philosophical inquiry (Daniel and Auriac, 2011; Garratt and Piper, 2011; Daniel, 2008; Trickey and Topping, 2007). The practice adopted in the present study, CoPI, is a practical philosophy devised by Catherine McCall following her work with Matthew Lipman and his Philosophy for Children (P4C) progamme (Lipman, 2003) in the 1970s (McCall, 2009). Participants engage in structured philosophical dialogue. In being seen as a practical philosophy, children are not expected to learn about philosophers and their ideas, instead they engage with a range of ideas through dialogue that is philosophical in nature.

McCall's approach to Philosophy with Children (PwC) is different to other PwC practices, though there are certain elements in common. Lipman based his $\mathrm{P} 4 \mathrm{C}$ programme on the promotion of democratic goals such as the creation of reflective, autonomous, critical thinkers (Lipman, 2003). Not only might the aims of Lipman's P4C be described as democratic, some of the practice, and the approaches that derive from it, also adopt what may be seen as democratic approaches, such as children voting for questions to be discussed. While McCall's CoPI was developed from her work with Lipman, her approach is different. 
It shares the aims of supporting participants to be critical and reflective in their outlook, that they work to examine their thinking and the thinking of others, but CoPI's structure is different. The facilitator's interventions are less obvious than in other approaches and she does not contribute to the content of the dialogue itself. There is, in addition, no conclusion or consensus sought in CoPI.

All PwC is structured in some way, but CoPI's structure is based on a series of rules (see Cassidy et al, 2014) that are similar, but not the same as other approaches. In CoPI it is this very structure that affords freedom for the participants. A trained facilitator who has a formal/academic, philosophical background, that it is assumed the participants do not, leads the sessions. Her role is to select a stimulus that will raise philosophical questions for the participants. Unlike some other approaches, the participants' questions are used in CoPI (Cassidy, 2012). This means that the children have ownership of the dialogue from the beginning and this is designed to support their investment in the dialogue. The children, though, do not select the question for discussion. The facilitator, drawing upon her background knowledge of philosophy, chooses the question with the most philosophical potential. Some PwC practices allow participants to vote for or choose the question for investigation. This, though, may lead to a less philosophically focused question being chosen or, and this is important here, one that is asked by the most popular, articulate or confident child in the class (Cassidy, 2012).

While this may appear to be anti-democratic or limiting the participants in their engagement, it can be argued that it is this structure that is enabling. The participants can engage in the dialogue freely and can drive the topic in any direction they choose and the facilitator must follow. In P4C, by contrast, discussion plans are followed where the facilitator has an 
agenda. The only agenda in facilitating McCall's CoPI is that the dialogue is as philosophically strong as possible, which is supported by the facilitator intervening to request an example of a point made, to ask for an explanation of a word or term, or in juxtaposing speakers to ensure disagreement - for without disagreement there would be no philosophy. The CoPI facilitator never offers her own opinion or comment, never draws conclusions from what has been said and does not interpret the participants' contributions as may be seen in other PwC approaches.

CoPI is structured in such a way that when speaking, in response to the question posed, participants must raise their hand should they wish to contribute. This allows the facilitator to select the speakers in an order that is likely to juxtapose ideas to move the dialogue forward philosophically. When speaking, participants begin by either agreeing or disagreeing with a previous contribution and give reasons for this agreement/disagreement. This enables them to make connections between contributions in order that ideas can be built upon. No technical language or jargon may be used as this is exclusive; everyday language should be used. Speakers are not permitted to refer to authorities such as those found in books, television or their families for their reasons as it is the participants' own thinking that is valued. Participants' contributions need not be personally held opinions, allowing them to experiment with ideas. There is no search for conclusion or consensus in the dialogue, unlike in some PwC approaches, because it is desirable that the participants keep thinking and questioning after the session has ended. The stimulus used will enable children to ask questions about the nature of reality, justice, knowledge, a good life, art, and the like; a range of topics very similar to those of adults involved in CoPI (Cassidy, 2012). 
In addition to there being a clear structure and set of rules for CoPI, there are further aspects of the practice that may be expected to support participants who might otherwise be marginalised. In the first instance, seating the participants in a circle indicates that no-one is privileged in their participation and that all are equally valued (McCall, 2009). Sitting in a circle also allows each child to see and be seen by all participants, their presence, therefore, cannot be ignored. The facilitator, however, remains outside the circle in order to see all participants that she might contrastively sequence the contributions in her selection of speakers. More importantly, in remaining outside the circle, children are less inclined to defer to the teacher for confirmation or validation of their contributions; instead, the participants engage with one another on equal terms and the adult's role is to support the development of the dialogue by carefully employed interventions for clarity; she should be as unobtrusive as possible. Reading the stimulus text aloud, either altogether or individuals reading small sections in turn, offers a shared experience to begin the session; no participant has additional information prior to the session. It should be noted that where there may be difficulties in reading aloud, participants can read with the facilitator leading the reading. This reading aloud is important in terms of the participants sharing something in common, but also in the participants having the opportunity to hear their voices out loud and within the Community.

Participants must raise their hands and wait to be called should they wish to make a contribution. The facilitator selects the speakers in an order that takes into account how they might contribute to taking the dialogue forward. All children have an equal opportunity to be selected and to have their voices heard. Similarly, if children do not wish to speak they are able to listen without the pressure or worry that they will be asked for their views, a feature that is particularly important for children with some ASN. What is also worth noting is that all children, should they volunteer, will be invited to contribute. In what might be considered 
normal discussions, children who are marginalised, or at risk of being marginalised, will often have their participation diminished or blocked by more dominant participants (McCall, 2009; Cassidy, 2012). Should a participant be overly dominant in normal discussions, this is not possible in CoPI due to the facilitator taking responsibility to ensure that a balanced dialogue occurs where as many perspectives as possible are explored. As noted above, there is a clear structure to participants' contributions in CoPI. By offering the 'I agree/disagree with... because...' format all participants can gain entry to the dialogue. In other classroom discussion sessions they might find it difficult to articulate their ideas and make links to others in a coherent manner. This element of the practice facilitates connections for the listener as well as the speaker.

When speaking, participants are not permitted to use technical language or jargon whether related to philosophy, football, computers, or any other topic that might be introduced to the dialogue. This allows a more equalising platform, since any word or term that may act as a barrier to understanding must be explained in order that every participant might understand what is being said (Cassidy, 2007).

Finally, there is no search in CoPI for a consensus or conclusion. A search for consensus or conclusions happens in some PwC approaches but it is held, here, that in reaching a conclusion or seeking consensus some views become more privileged than others, suggesting that the question has been answered and that there is, therefore, no need for further inquiry in this area. It allows that all contributions are valued and necessary as each builds upon prior contributions. This is not to say that all comments are equally worthwhile; indeed, some contributions may be made and no further reference made to them. However, participants 
may return later in a dialogue or subsequent dialogues to comments that have been made and apparently left aside at any particular point. No participant's contribution stands alone and children realise very quickly that the community aspect of shared meaning making is crucial for CoPI to work, thus emphasising the communal and inclusive nature of the dialogue. This might be particularly important to children whose voices may otherwise be marginalised in other class activity.

While having a structure for dialogue may be seen as limiting and open discussion may be seen as the most desirable approach to exploring ideas in a classroom, there are some issues with open discussion, particularly for marginalised children, that the project and the use of CoPI aimed to address. It is, therefore, the predictable structure of CoPI that might be seen as enabling for marginalised children. For those who struggle with turn-taking or who are anxious about being asked to speak in a group or when they are unsure of what to say, or who find it difficult to self-regulate some of their behaviours or who lack confidence, the regular and simple structure of CoPI may be supportive. The hypothesis in adopting CoPI with marginalised children was that in adhering to the structure, the participants would be freed to engage with the ideas and to determine for themselves whether they agree or disagree with what they hear and why this may be the case. It was proposed that children who may not normally be heard in the classroom, either because they lack confidence to speak out or because they have difficulty with self-regulation, would have an opportunity to speak and for others to listen and that the CoPI structure would support them in making their contributions in a way that allows them to connect with others and have others connect with their ideas. The facilitator only provides the structure to support the thinking, the ideas are generated by the children themselves and they work together to search for meaning or understanding. 


\section{Children's voices}

The issue of having a voice is also particularly relevant to marginalised children and may be understood in terms of four distinct but related components: space; voice; audience; and influence when Lundy (2007) discusses this in relation to Article 12 of the UNCRC. It might be hypothesised that CoPI could provide a safe, structured 'space' within which individuals are enabled to express and share views and ideas - should they choose to do so. The structure also ensures that there is an 'audience' for individuals' views, since subsequent participants have to engage with previous contributions by indicating agreement/disagreement and providing reasons for such. This, in turn, provides feedback to the participants, indicating not only that their contributions have been listened to, but that they are having an 'influence' on those around them because each contribution shapes the evolving dialogue by successively eliciting responsive turns.

In adopting CoPI for this project, opportunities would be provided for children to engage in dialogue. In doing so, they would be able to practise their voices in terms of speaking about their own ideas and the ideas of their peers without the influence of an adult on the content or focus of the dialogue itself. It could be suggested that the structure is limiting, but for the reasons noted previously, CoPI was considered to be more enabling than some other PwC approaches and that the structure would, in fact, free the children to engage in the dialogue and develop their critical thinking in order that they may engage more fully beyond the confines of the school. This article does not aim to address the influence of the children's voices, though the children's adoption of the structure into other contexts to support them in exercising their voices is discussed elsewhere (Cassidy et al, under review). In addition, in 
following a structure, participants may come to understand that some structures are important and can be facilitative, that not all imposed structures need be negative. One should note, as an aside perhaps, that CoPI is practised with adult groups in the same manner in which it is undertaken with children, that what is true for children is also true for some adults; that they need support and practise in articulating ideas, providing reasons, in argument, and in reasoning. CoPI offers a secure environment to practise those skills required for living in a democracy where they may not be present elsewhere in people's lives - regardless of age. In CoPI, unlike in a democratic society or community more generally, the power resides with the children in terms of ownership of the dialogue and whether they choose to exercise their voices.

\section{Methodology}

This article focuses on case studies of three children who might be considered marginalised on account of their recognised ASN. These children were selected from three classes of children who undertook regular CoPI sessions as part of their normal class work in classes that were involved in a larger study exploring the potential value of CoPI in a range of educational contexts (Cassidy et al., 2013). The present study was designed to explore the level and quality of engagement of each of these children and to relate this to other available information about each individual child in order to ascertain the ways in which CoPI might support and benefit children who may be considered marginalised.

All three children participated, as part of their school routine, in CoPI with teachers trained in its facilitation. The children belonged to three schools in the West of Scotland. School A is a 
primary school that uses an approach to the curriculum where children are in 'skills classes' with children of their own age for part of each morning. For the rest of the school day, the children move to other classes, 'community classes', where they learn with their peers across the age range of either primary one to primary four (ages five to eight) or from primary five to primary seven (ages nine to twelve). In these community classes children learn collaboratively in smaller classes using an interdisciplinary, cross-curricular approach. School B is a traditional primary school where children are placed in one class for the whole week with children of the same age. The class in School B, however, participated in the project with the support of a visiting teacher who undertook the CoPI sessions, so she was not their teacher throughout the rest of the week. School C was a large secondary school with 1,640 pupils. The teacher in the study was the Religious, Moral and Philosophy Studies (RMPS) teacher who conducted CoPI sessions as part of the planned RMPS curriculum for this particular class.

The three children were chosen for consideration in the study by their class teachers. They were not the only children in the classes with ASN. The main selection criterion was that the combination of their individual circumstances and contextual factors was such that they were considered by their class teachers most likely to be marginalised within their particular school context. All children have been given pseudonyms.

\section{Angus}

Angus attends School A and is nine years-old. Following referral by the school, he is being assessed by the educational psychologist, though no specific named difficulties have as yet 
been identified. He seriously lacks confidence in his academic work and this manifests itself in challenging behaviour in the class. He is currently on a coordinated support plan (CSP) and works with a specialist support teacher on a regular basis. The CSP is a structured process of intervention designed to meet the individual child's ASN. When talking in class discussions or in one-to-one situations, Angus becomes over-excited and flustered because he loses track of the conversation and becomes frustrated. He struggles to express himself with adults and peers alike. He is often violent as a consequence of being upset when he is not coping. He shouts out in class and makes faces at others or kicks them when they say things he does not like or that disagree with his views.

\section{Bruce}

Bruce attends School B and is ten years-old. He has been diagnosed as having Autistic Spectrum Disorder (ASD). Bruce shows great difficulty in regulating his emotions generally, and becomes angry and aggressive with other children and adults. He requires consistent, tight structures during the school day and does not cope with changes, for example, in timetabling. He has a key worker who is in attendance at all times to support him. He is often removed from the class due to his aggressive behaviour and he does not like to sit with the other children as part of a group.

\section{Catriona}

Catriona attends School C and is thirteen years-old. She is a member of the school's Nurture group (Boxall and Lucas 2010), a small group arrangement within the school context, intended to provide the kinds of nurturing experiences normally assumed to be provided by a 
caring home environment and designed for children who have ASN in the emotional and social domain that would be difficult to meet in conventional classroom conditions. Catriona has particular difficulties with self-confidence and resilience. In addition to being a member of the Nurture Group, Catriona has regular support from a sixth year pupil (aged seventeen) who acts as a 'buddy' in several of her classes and during break times.

Each class participated in CoPI once a week for ten weeks with each session lasting approximately one hour. Each class used the story Laura and Paul (McCall 2006), written specifically for CoPI with children, as their stimulus. The evidence for the present study was generated in three ways by the class teachers involved, as required for the larger study (Cassidy et al., under review). Firstly, teachers maintained observational records of pupils' engagement and participation. This involved them in considering, amongst other things, the pupils' contributions to the sessions, their distracting or engaged behaviours and their patience while waiting to speak. Secondly, each teacher audio-recorded samples of the dialogues across the ten weeks. Thirdly, they kept reflective logs noting significant incidents and/or behaviours within the CoPI sessions and other class activity as appropriate within their context. The reflective logs contain comments noted by the teachers from the children and also other teachers or parents associated with the children. This means that observations from the facilitating teachers could be supported by the inclusion of comments noted from others. The evidence in the present study mainly focuses on the content of these reflective logs relating to the three children selected as case studies. The findings of the larger study are reported elsewhere (Cassidy et al, under review).

\section{Evidence}




\section{Angus}

In contrast to his behaviour in conventional classroom activities which tended to be characterised by frustration with communication and interaction, from the outset Angus responded very positively to participating in CoPI sessions. He wanted to take part and was engaged in what was being said, wanting to contribute himself. This does not mean that his challenging classroom behaviour was not initially present; it is simply that he wanted to engage in doing CoPI. His teacher reported that he 'Loves speaking in CoPI'. However, to begin with he found it difficult to accept others' disagreement with his statements and he only ever disagreed with those that had disagreed with him and he found it very hard not to take it personally when they did. Indeed, Angus was known for making faces or having violent outbursts at those who disagreed with him, though over time he stopped making faces and staring at children who disagreed with him and the violent behaviour stopped during the sessions.

Over the ten weeks, Angus became much more open to agreement and disagreement with others and by halfway through the sessions he agreed/disagreed freely within the dialogue. In fact, towards the end of the ten weeks he was able to agree and disagree within one contribution. This is complex for any participant, but for Angus this represented a major achievement, given his particular communication difficulties. The teacher noted that because he was not rushed in making his contributions he was able to sit quite still to formulate his ideas and became less flustered and calmer during the sessions, making contributions that were increasingly better structured. She also noted that he seemed better able to remember what he wanted to say during the dialogue and in other contexts. 
By the final week Angus was able to look at the speakers while they were speaking, this being a change in his demeanour over the course of the sessions. The teacher reported that Angus became much more confident in articulating his ideas as the weeks progressed. Angus said to the teacher that he became more excited to be in the group and really enjoyed the sessions, that they were fun because, 'Once that thought is in your head it's a brilliant thing. It's a brilliant thought'. As time went on Angus increasingly contributed to the dialogue in meaningful ways that pushed the dialogue further.

The teacher noted that the improvement in his ability to interact in such a positive way extended beyond the CoPI sessions and transferred into other class contexts involving collaborative groupwork where he was observed to be working well with others, listening to their contributions and ideas.

Additionally, when speaking with adults beyond the classroom context, Angus used the structure of agreeing/disagreeing, taking his time to speak to support him in conversations. Angus himself reported to the teacher that he used the agree/disagree structure at home, saying, 'I use it with my mum and dad'; this being a good example of the structure being enabling by supporting Angus beyond the classroom. The teacher's log also recorded that the positive changes in Angus' behaviour were being noticed and acknowledged by the school's senior management team. The improvement in Angus' general demeanour and wider school context is captured in the following passage from the teacher's log:

He was trying to tell me something that happened in the playground and he was overexcited. He actually recognised this and stopped, thought what he wanted to say and 
started again. He didn't get annoyed or just not continue the conversation which he would have done in the past as he would get so flustered. It's helped him have confidence in himself and he seems to now allow thinking time to formulate his thoughts.

\section{Bruce}

Bruce attended seven of the ten CoPI sessions. It is worth noting that on the first week Bruce went looking for his own chair and very quickly identified it as his and sat on it. Before the session began the teacher reported asking everyone to move to another seat, as she did every week. Unusually, Bruce did this without any fuss or protesting. During normal class time Bruce always opted to sit at his desk while the other children congregated around the teacher, seated on the carpet for group discussion. He disliked the disorder and clutter of sitting with the other children on these occasions. However, from the outset the teacher noted that Bruce joined the circle with the other children at the start of every session and did not make a fuss about not being able to sit at his own desk. As noted above, Bruce was always accompanied by a dedicated key worker during all classroom activities. However, it was noteworthy that this key worker did not attend CoPI sessions and Bruce did not display any of the negative behaviours that would have been expected in other circumstances.

In session one Bruce offered a question which was selected for discussion. However, after making an initial contribution he did not attempt to engage again. Bruce was visibly frustrated during the first three sessions stating that he was angry because the other children were disagreeing with him. He removed himself from these sessions but always returned of 
his own volition. Over the ten weeks Bruce stopped removing himself from the sessions and said to his teacher that he did not mind people disagreeing with him and said he liked talking. The teacher's log suggests that the difficulty Bruce had in terms of regulating his emotional reactions was tempered by participating in CoPI. She recorded that Bruce no longer appeared to be frustrated by the structure of CoPI and was observed consistently to follow the structure appropriately himself. Further, the teacher reported that he contributed meaningfully to the dialogue over the sessions and that on the occasions when he was absent the other participants missed his contributions. The teacher recorded that Bruce 'very quickly became a key member of the group' and while he was reluctant to participate in group discussion in normal classroom activity, she reported, 'I genuinely feel that Bruce was given a voice during CoPI'.

\section{Catriona}

As the context here is secondary school where the children change classes for different subjects, the class teacher, as well as recording her own observations, gathered relevant information about Catriona from her other class teachers.

The teacher reported that Catriona was isolated in class, choosing to sit with her allocated buddy, but not with any of her class mates. She was generally hard-working and would apply herself to independent tasks, but would not take an active role in team tasks or whole class discussions. She would, however, speak comfortably to her class teacher and buddy. During the initial CoPI sessions, Catriona listened attentively to others, but would not volunteer questions or ideas. Gradually, she made tentative contributions, but these would often not be 
in line with the CoPI structure and sometimes lacked relevance to the discussion. However, she soon began to volunteer questions, that were also relevant to the discussion. By the end of the ten weeks, the teacher reported, 'Catriona now frequently makes contributions which are relevant and can lend a new and positive direction to the dialogue'.

The teacher also noted that Catriona became more comfortable working with her peers and, during classroom activity, choosing to sit with and work with others, being fully involved in independent, team and whole class tasks. One example from the teacher's log illustrates how Catriona had become more confident in her classwork and interactions with others is when she reports:

For our end of unit assessment of our Arguments in Action unit, pupils were given the choice over how they would like to be assessed. Some chose written assessments, some chose oral assessments, one girl wrote a song and Catriona chose to work with a partner to produce a presentation on what they had learned and to teach this to an entire SI [year one] class. The S1 class were to grade the girls and to give feedback. The overwhelming opinion of the class was that the girls were to get a grade A.

The teacher provided information to support this change in Catriona's confidence and engagement by recording comments from other subject teachers. For example, in English her teacher indicates in the following statement that Catriona

... appears to have gained in confidence over the session and is more likely to ask for assistance than at the start of S2 [year two]. Also, she seems rather more willing to engage with the teacher as she enters/leaves the room than was originally the case. Catriona answers out more regularly and appears to be more relaxed/happy in class. 
Another example is provided by Catriona's Business Studies teacher, reporting that she has ...seen a remarkable improvement in Catriona over the short space of time. She confidently prepared a PowerPoint presentation ... and presented it with confidence to the whole class. She was able to answer questions that pupils asked and to give examples. She is more willing to contribute to class discussions.

Indeed, the teacher responsible for the school's Nurture Group reported that their focus was on developing Catriona's self-confidence and resilience. Her observations of Catriona since taking part in CoPI sessions indicate that

She is now more confident and willing to contribute to group discussion. She used to have lots of fallouts with her peers and find it difficult to resolve them without adult intervention. She appears to be dealing with these types of conflict more effectively now. There was a big fallout in one class last month and afterwards she managed to reflect on what had happened and deal with the situation in a mature way. This was certainly an improvement from previous incidents.

\section{Discussion and conclusion}

The children selected for this study were deemed to be at risk of marginalisation due to their ASN and the traditional structures within which classrooms operate. The evidence shows that all three children benefitted from their participation in CoPI. What is noteworthy is that each teacher reported gains in the children's confidence as well as social competence. In relation to Curriculum for Excellence capacities for the three marginalised children presented here, the issue of a lack of confidence has emerged as having been a barrier to their participation and, in turn, their learning. The structure of CoPI and the experience of becoming 'Effective 
Contributors' (Scottish Executive, 2004) to classroom dialogue appears to have improved their sense of self-confidence as reported by their teachers.

The evidence confirms, for these three children at least, the hypothesis that CoPI provides a safe, structured 'space' (Lundy, 2007) within which individuals can express and share views. This resonates with the Wegerif's (2011) concept of 'dialogic space'. All three children in their own distinctive ways, showed increased confidence in themselves as participants by speaking out more readily in the dialogues and in accepting that others might disagree with them. The structure also appears, in Lundy's terms, to have provided an 'audience' for their individual views. This audience allows the speaker to take time to formulate and express her ideas with the consequent that the speakers remain calm while waiting to speak and while actually contributing. Owing to the requirement of subsequent speakers to agree/disagree with what has been said, by building upon others' contributions, this in turn provides feedback that their expressed views are having an 'influence' on the views and ideas of the other participants, thereby shaping the evolving dialogue. Thinking about Angus in particular, for example, the safe space provided by the structure of CoPI enabled him to gather his thoughts and articulate what proved to be meaningful and significant contributions to the dialogue without being hampered by the frustration caused by less structured contexts in which he usually found himself. He also had the option to continue to be violent and disruptive in the class but chose not to. Similarly, as Bruce became more familiar with the structured space provided by CoPI, he was progressively able to focus on the content of the dialogue and recognised his role in driving this forward and stayed within the group rather than removing himself as he did in the early sessions. Catriona overcame her initial lack of confidence as she became comfortable with the format and structure of the CoPI sessions. In keeping with the others, this confidence transferred into other classroom contexts. 
The notion of 'Confident Individuals' (Scottish Executive, 2004) is key to CfE as one of the four interlinked capacities to be developed in developing effective contributors and responsible citizens since without confidence children will be limited in their ability to participate and engage as active citizens in the world around them, be that in school or the wider community. In each of the documented case studies, the link between growing confidence and meaningful participation in classroom life is particularly clear and appears to have been fostered by the key characteristics of CoPI as a powerful pedagogical tool. It might be argued that allowing children to own the dialogue is an important factor in promoting children's engagement and confidence, where in traditional classroom contexts the teacher is ever present within the group and may be seen to hold the answers while also orchestrating the flow of class discussion. In CoPI, however, the facilitator follows the direction in which the participants take the dialogue and is, therefore, more responsive, without actually contributing to the dialogue itself. This is a powerful illustration of a shift in power in the classroom that encourages pupil self-regulation (Zimmerman, 2008). Similarly, that all contributions are equally valued is particularly important for children at risk of marginalisation, as was shown by Catriona who normally abstracted herself from group situations. Further, the agree/disagree structure was clearly understood and internalised by the three children whose teachers reported that they readily transferred the format into other situations, with Angus stating that he used this beyond school in his personal life. It is hoped that this emerging confidence will support the children towards fuller engagement as citizens.

In determining how CoPI might make a difference in children's lives, particularly those who are marginalised, we have to look at its structure. The dialogue itself may be engaging, but it 
is through the structure that we can see how children have been able to engage and air their ideas. It can be argued that the predictable and facilitated structure has enabled the children within the classroom. By knowing that they have the choice to speak or not, that they can say what they want in exploring their own questions, that they have an opportunity to speak without the teacher making judgements, that they are part of a community that works together in a way that is not common in classrooms can be understood to be of great importance to marginalised children. For children who are anxious, such as Catriona, they can relax that they will not be called upon without volunteering, for children like Angus, the rules of turntaking, but also that others will listen and respond positively are supportive, and for children like Bruce with ASD, CoPI's rules are predictable and reassuring. It is, therefore, argued that CoPI's structure creates a flexible space for the expression of children's ideas through collaborative dialogue.

Rather than adopting a behaviourist approach that rewards and punishes certain behaviours, using the likes of CoPI allows for a more inclusive classroom; one in which children's voices are valued and they determine how they will engage. Given that the case study children responded so positively to the interestingly liberating structure of CoPI, it is suggested that this approach to education for citizenship might be particularly enabling for children who are marginalised. The approach could be said to support children in their thinking, reasoning and practising their voices by including them in a Community of Philosophical Inquiry where they see that they and their contributions are valued. It should be said, though, that whatever is true for marginalised children is true for all children. 


\section{References}

Bartels R, Onstenk J and Veuglers W (2015) Philosophy for Democracy. Compare: A Journal of Comparative and International Education. Epub ahead of print 9 July 2015. DOI: $10.1080 / 03057925.2015 .1041367$

Biesta G (2008) What kind of citizen? What kind of democracy? Citizenship education and the Scottish Curriculum for Excellence. Scottish Educational Review 40 (2): 38-52.

Biesta G, Lawy R and Kelly N (2009) Understanding young people's citizenship learning in everyday life: The role of contexts, relationships and dispositions. Education, Citizenship and Social Justice 5 (4): 5-24.

Boxall M and Lucas S (2010) Nurture Groups in Schools: Principles and Practice (Second Edition). London: Sage.

Cassidy, C (2007) Thinking Children. London: Continuum.

Cassidy, C (2012) Questioning Children. Thinking: the Journal of Philosophy for Children 20 (1\&2): 62-68.

Cassidy, C and Christie, D (2013) Philosophy with Children: talking, thinking and learning together. Early Child Development and Care 183 (8): 1072-1083.

Cassidy, C and Christie, D (2014) Community of Philosophical Inquiry: citizenship in the classroom. Childhood \& Philosophy 10 (19): 33-54.

Cassidy et al. (under review)

Conn C (2014) Investigating the social engagement of children with autism in mainstream schools for the purpose of identifying learning targets. Journal of Research in Special Educational Needs 14 (3): 153-159. 
Daniel M-F (2008) Learning to philosophize: positive impacts and conditions for implementation. A synthesis of 10 years of research (1995 - 2005). Thinking 18 (4): 36-48. Daniel M-F and Auriac E (2011) Philosophy, critical thinking and Philosophy for Children. Educational Philosophy and Theory 43 (5): 415-435.

Florian L and Spratt J (2013) Enacting inclusion: a framework for interrogating inclusive practice. European Journal of Special Needs Education 28 (2): 119-135.

Garratt D and Piper H (2011) Citizenship education and philosophical enquiry: Putting thinking back into practice. Education, Citizenship and Social Justice, 7 (1): 71-84.

Kennedy D (2006) The Well of Being. Childhood, Subjectivity, and Education. Albany: SUNY Press.

Lipman M (2003) Thinking in Education (Second Edition). New York: Cambridge University Press.

Lundy L (2007) 'Voice' is not Enough: Conceptualising Article 12 of the United Nations Convention on the Rights of the Child. British Educational Research Journal 33 (6): 927942.

MacNaughton G, Hughes P and Smith K (2007) Young Children's Rights and Public Policy: Practices and Possibilities for Citizenship in the Early Years. Children \& Society 21: 458469.

McCall C (1991) Stevenson Lectures on Citizenship. Glasgow: Glasgow University Press. McCall C (2006) Laura and Paul. Oxford: Trafford Publishing. McCall C (2009) Transforming Thinking: Philosophical Inquiry in the Primary and Secondary Classroom. London: Routledge.

Messiou K (2012) Collaborating with children in exploring marginalisation: an approach to inclusive education. International Journal of Inclusive Education 16 (12): 1311-1322. 
Moscardini L (2013) Additional Support Needs. In: Bryce TGK, Humes WA, Gillies D and Kennedy A (eds) Scottish Education (Fourth Edition): Referendum. Edinburgh: Edinburgh University Press, pp. 796-808.

Scottish Executive (2004) A Curriculum for Excellence. Edinburgh: Scottish Executive. Stables A (2008) Childhood and the Philosophy of Education. An Anti-Aristotelian Perspective. London: Continuum.

Topping KJ and Trickey S (2007). Collaborative philosophical enquiry for school children: cognitive effects at 10-12 years. British Journal of Educational Psychology 77 (2): 271-288. Veuglers W (2007) Creating critical-democratic citizenship education: empowering humanity and democracy in Dutch education. Compare: A Journal of Comparative and International Education 37 (1): 105-119.

Wall J (2011) Can democracy represent children? Towards a politics of difference. Childhood 19 (1): 86-100.

Wegerif R (2011) Towards a dialogic theory of how children learn to think. Thinking Skills and Creativity 6: 179-190.

Zimmerman B (2008) Investigating self-regulation and motivation: historical background, methodological developments, and future prospects. American Educational Research Journal 45: $166-183$. 